Kansas State University Libraries

New Prairie Press

\title{
COMPARING CORRELATED PARAMETER ESTIMATES FOR NONLINEAR PET MODEL
}

J. Wu
A. Parkhurst
K. Eskridge
D. Travnicek
T. Brown-Brandl

See next page for additional authors

Follow this and additional works at: https://newprairiepress.org/agstatconference

Part of the Agriculture Commons, and the Applied Statistics Commons

\section{(c) (1) $\Theta$}

This work is licensed under a Creative Commons Attribution-Noncommercial-No Derivative Works 4.0 License.

\section{Recommended Citation}

Wu, J.; Parkhurst, A.; Eskridge, K.; Travnicek, D.; Brown-Brandl, T.; Eigenberg, R.; Hahn, G. L.; Nienaber, J.; Mader, T.; and Spiers, D. (2003). "COMPARING CORRELATED PARAMETER ESTIMATES FOR NONLINEAR PET MODEL," Conference on Applied Statistics in Agriculture. https://doi.org/10.4148/2475-7772.1193

This is brought to you for free and open access by the Conferences at New Prairie Press. It has been accepted for inclusion in Conference on Applied Statistics in Agriculture by an authorized administrator of New Prairie Press. For more information, please contact cads@k-state.edu. 
Author Information

J. Wu, A. Parkhurst, K. Eskridge, D. Travnicek, T. Brown-Brandl, R. Eigenberg, G. L. Hahn, J. Nienaber, T. Mader, and D. Spiers 


\title{
COMPARING CORRELATED PARAMETER ESTIMATES FOR NONLINEAR PET MODEL
}

\author{
J. Wu ${ }^{1}$, A. Parkhurst ${ }^{1}$, K. Eskridge ${ }^{1}$, D. Travnicek ${ }^{1}$, T. Brown-Brandl ${ }^{2}$,R. Eigenberg ${ }^{2}$, \\ G.L.Hahn ${ }^{2}$, J. Nienaber ${ }^{2}$, T. Mader ${ }^{3}$, and D.Spiers ${ }^{4}$ \\ 1. Department of Biometry, University of Nebraska \\ 2. U.S. Meat Animal Research Center, U.S.D.A, Clay Center, NE \\ 3. Department of Animal Science, University of Nebraska \\ 4. Department of Animal Science, University of Missouri - Columbia
}

\begin{abstract}
The nonlinear PET model based on Newton's law of cooling can be used to estimate body temperature in cattle, $T_{b}$ challenged by hot cyclic chamber temperatures, $T_{a}$. The PET model has four biologically meaningful parameters: $K$, the thermal constant; $\Delta$, the difference between $T_{b}$ and adjusted $T_{a} ; \gamma$, the proportion of variation in $T_{b}$ comparable to variation in $T_{a} ; \mathrm{T}_{\text {bini, }}$, the initial body temperature. The two parameters $\gamma$ and $\Delta$ are highly correlated in the current version of the model. This study looks at other ways to parameterize the PET model in an effort to reduce the correlation between parameters and improve nonlinear behaviors, such as parameter-effects curvature, bias, excess variance and skewness.
\end{abstract}

Key Words: Nonlinear, PET model, parameterize, nonlinear behavior, curvature, bias, excess variance, skewness, correlation.

\section{Introduction}

The nonlinear PET model was developed by Parkhurst, Eskridge and Travnicek (1999), to estimate body temperature in cattle challenged by hot cyclic chamber temperature. The model assumes that when cattle are under heat stress, air temperature, $T_{a}$ is the principle driving force influencing body temperature, $T_{b}$ (Hahn, 1989). The effect of Ta on Tb follows "Newton's law of cooling"; i.e., the rate of change in animal body temperature, from the body core to its surface, is proportional to the difference in temperature between the body core and its environment. It can be written as a one-parameter mathematical model: $\frac{\partial T_{b}}{\partial t}=\kappa\left(T_{a}-T_{b}\right)$, where $K$ is a thermal constant that represents how rapidly $T_{b}$ adjusts to changes in $T_{a}$. The thermal constant is measured in units per time and $T_{a}$ is usually regarded as constant in time. But the animals in this study were enclosed in a hot cyclic environment. So, $T_{a}$ is modeled by the following sinusoidal function:

$$
T_{a}=\mu_{a}+\mathrm{A} \sin \{\omega(\mathrm{t}-\varphi)\}
$$

where $\mu_{a}$ is mean air temperature, $\mathrm{A}$ is amplitude, $\omega$ is frequency, $\mathrm{t}$ is time and $\varphi$ is phase angle. 
A useful solution that is a function of Newton's differential equation is the following model (Parkhurst, et.al, 2000):

$$
T_{b}=e^{-\kappa^{*} t}\left(K^{*}\left(S_{0}+S_{1}\right)+T_{\text {bini }}\right),
$$

where $\mathrm{T}_{\text {bini }}$ is the initial body temperature;

$$
\begin{gathered}
S_{0}=\left(\gamma * \mu_{a}+\Delta\right)^{*}\left(e^{\kappa^{* t}}-1\right) / \kappa \\
S_{1}=\left(\mathrm{A}^{*} \gamma /\left(\sqrt{\kappa^{2}+\omega^{2}}\right)\right)^{*} e^{\kappa^{* t}}(\sin (\omega(\mathrm{t}-\varphi-\{\arctan (\omega / \kappa)\} / \omega)) \\
+\sin (\omega(\varphi+\{\arctan (\omega / \kappa)\} / \omega))) ;
\end{gathered}
$$

$\gamma$ represents the proportion of average $T_{a}$ passed on to the average $T_{b} ; \Delta=\mu_{b}-\gamma \mu_{a}$ is the gradient parameter which represents the difference between $\mu_{\mathrm{b}}$, (the average $T_{b}$ ) and adjusted average $T_{a}$. Frequently, it is helpful to convert $\kappa$ to $\tau$, the length of time that $T_{b}$ lags behind $T_{a}$.

There are four parameters in this model: $K, \mathrm{~T}_{\text {bini }}, \Delta, \gamma$. Of the four parameters in the model, one of the most important parameters to measure acclimation of steers to heat stress is the lag, $\tau$, which is a function of $K$. However, this parameter is highly correlated with $\gamma$ and $\Delta$. Moreover $\gamma$ and $\Delta$ are highly correlated with each other. And, while correlations among parameters is typical in nonlinear regression models, high values may indicate overparameterizaton. Another problem is that the nonlinear behaviors of these parameters are not ideal.

One way to solve these problems is to reparameterize this model. Parameterization is the process of expressing the mean function of a statistical model in terms of parameters to be estimated. A particular parameterization may be chosen so that the parameter estimators have a pertinent interpretation, desirable statistical properties, and/or allow embedding of hypotheses.

A nonlinear model can be parameterized in different ways. Two ways discussed by Schabenger and Pierce (2000) are called defining relationships and expected values. The technique called defining relationships consists of creating a new parameter that is a function of the original parameter(s). The new parameter is then substituted into the original model.

The expected value parameterization technique due to Ratkowsky (1983) consists of rewriting the model in an expected value parameterization in order to reduce the parametereffects curvature and make the estimates of the parameters more Gaussian-distributed, less biased, less correlated and make their standard error estimates more reliable. Furthermore, the model usually converges more rapidly (Schabenger and Pierce, 2000). Expected-value parameters exhibit close-to-linear behavior because the bias in predicted values depends only on the intrinsic nonlinearity (Ratkowsky, 1983) and the intrinsic nonlinearity is typically small for useful model-data sets. The only restriction on expected-value parameters is that they should fall within the observed range of the data and not correspond to asymptotes or extrapolations outside the data range.

Ratkowsky's expected-value parameters correspond to the fitted (or predicted) values of the response variable. To find expected-value parameters, choose $\mathrm{p}$ values of the explanatory variable $t_{1}, t_{2}, \ldots \ldots t_{p}, p$ being the number of parameters, set the expected values equal to $Y_{1}$, 
$\mathrm{Y}_{2}, \ldots \ldots, \mathrm{Y}_{\mathrm{p}}$, then substitute each pair of $\mathrm{t}$ and $\mathrm{Y}$ into the model to get $\mathrm{p}$ equations. Then, one solves for the $\mathrm{p}$ original parameters from the $\mathrm{p}$ equations in term of the $\mathrm{p}$ explanatory variables $\mathrm{t}_{1}$, $t_{2}, \ldots \ldots t_{p}$ and the $p$ expected values $Y_{1}, Y_{2}, \ldots \ldots, Y_{p}$. Finally, the original parameters are eliminated after the parameter solutions are substituted into the original model (Ratkowsky, 1990).

The objective of this study is to find formulations of the PET model that have good estimation behavior and low parameter correlations. Reparamaterization and parameter reduction are used to: 1) improve nonlinear behaviors, such as parameter-effects curvature, bias, excess variance, and skewness; 2) reduce the correlation between parameters; and, 3) find a set of easily-interpreted parameters.

\section{Materials and Methods}

\section{2.a Data}

The data comes from a study conducted by T. Brown-Brandl, R. Eigenberg, and J.

Nienaber in 2001. That study was designed to evaluate the dynamics of thermoregulation when feeder cattle were exposed to simulated heat waves in comparison with repeated sinusoidal hot environments. Core body temperature from day six for one of the nine beef steers exposed to a controlled heat stress treatment of $32 \pm 7^{\circ} \mathrm{C}$ were used in this investigation. The observations started at 0:00am (Figure 1).

\section{B Reparameterizations}

\section{i. Direct Substitution Parameterizations:}

Parameterization 1:(Mean Body Temperature replacing $\Delta) \kappa, \mathrm{T}_{\text {bini }}, \mu_{b}, \gamma$. In the original PET model, there are four parameters: $\kappa, \mathrm{T}_{\text {bini }}, \Delta, \gamma$. But $\gamma$ is highly correlated with $\Delta$. Therefore, either $\gamma$ or $\Delta$ could be reparameterized by direct substitution. As stated in the introduction, $\Delta=\mu_{b}-\gamma \mu_{a}$. So, $\mu_{b}$ can be used to replace $\Delta$ and obtain the following model:

$$
\begin{gathered}
T_{b}=e^{-\kappa^{*} t}\left(\kappa *\left(S_{0}+S_{1}\right)+\mathrm{T}_{\text {bini }}\right) ; \\
S_{0}=\mu_{b}\left(e^{\kappa^{*} t}-1\right) / \kappa ; \\
S_{1}=\left(\mathrm{A} * \gamma /\left(\sqrt{\kappa^{2}+\omega^{2}}\right)\right)\left(e^{\kappa^{* t}} \sin (\omega(\mathrm{t}-\varphi-\{\arctan (\omega / \kappa)\} / \omega))\right. \\
+\sin (\omega(\varphi+\{\arctan (\omega / \kappa)\} / \omega))) .
\end{gathered}
$$

Parameterization 2: (Mean Body Temperature replacing $\gamma) \kappa, \mathrm{T}_{\text {bini }}, \Delta, \mu_{b}$. Similarly, $\mu_{b}$ can be used to replace $\gamma$ via the formula $\gamma=\left(\mu_{b}-\Delta\right) / \mu_{a}$ to obtain the following model:

$$
\begin{gathered}
T_{b}=e^{-\kappa^{*} t}\left(\kappa *\left(S_{0}+S_{1}\right)+\mathrm{T}_{\text {bini }}\right) ; \\
S_{0}=\mu_{b}\left(e^{\kappa^{*} t}-1\right) / \kappa ; \\
S_{1}=\left(\mathrm{A} *\left(\mu_{b}-\Delta\right) /\left(\mu_{a} \sqrt{\kappa^{2}+\omega^{2}}\right)\right)\left(e^{\kappa^{*} t} \sin (\omega(\mathrm{t}-\varphi-\{\arctan (\omega / \kappa)\} / \omega))+\right. \\
\sin (\omega(\varphi+\{\arctan (\omega / \kappa)\} / \omega))) .
\end{gathered}
$$




\section{ii. Combination: Expected-Value Parameterizations and Direct Relationships:}

Parameterization 3: (Body Temperature at 0:00am next day - Last time with thermal constant) $\kappa, \mathrm{T}_{\text {bini }}, \mathrm{T}_{\text {blast, }} \mu_{b}$. Use an expected-value parameterization to replace $\Delta$ based on the model with Parameterization 2. First set $t=t_{\text {last }}$, i.e. the last time value recorded. In this data, $t=t_{\text {last }}$ $=25$, i.e. 0:00 next day (figure 1 ) and set $T_{b}=T_{\text {blast, }}$ the body temperature when $t=t_{\text {last }}$ (figure 2 ).

Substitute the two variables into the model with parameterization 2 and solve parameter $\Delta$ in terms of $\mathrm{t}_{\text {last, }} \mathrm{T}_{\text {blast }}$ and the other parameters. Finally, $\mathrm{T}_{\text {blast }}$ can be used to replace $\Delta$ via the solved equation to obtain the reparameterized model:

$$
\begin{gathered}
T_{b}=e^{-\kappa^{* t}}\left(\kappa *\left(S_{0}+S_{1}\right)+\mathrm{T}_{\text {bini }}\right) ; \\
S_{0}=\mu_{b}\left(e^{\kappa^{* t}}-1\right) / \kappa ; \\
S_{1}=\left(\mathrm{T}_{\text {blast }} * \exp \left(\kappa * \mathrm{t}_{\text {last }}\right)-\mathrm{T}_{\text {bini }}-\mu_{b} *\left(\exp \left(\kappa * \mathrm{t}_{\text {last }}\right)-1\right)\right) / \kappa / \\
\left(-\exp \left(* \mathrm{t}_{\text {last }}\right) * \sin \left(-\omega *\left(\mathrm{t}_{\text {last }} \varphi\right)+\arctan (\omega / \kappa)\right)+\sin (\omega * \varphi+\arctan (\omega / \kappa))\right) *(\exp (\kappa * \mathrm{t}) \\
* \sin (\omega *(\mathrm{t} \varphi) \arctan (\omega / \kappa))+\sin (\omega * \varphi+\arctan (\omega / \kappa)) .
\end{gathered}
$$

Parameterization 4 (Body Temperature at 0:00am next day - Last time with lag): $\tau, \mathrm{T}_{\text {bini }}, \mathrm{T}_{\text {blast, }}$ $\mu_{b}$. Use $\tau$ to replace $K$ via the equation $\kappa=\omega / \tan (\tau \omega)$ to reduce parameter effects curvature based on the model with Parameterization 3 and obtain model:

$$
\begin{gathered}
T_{b}=\exp \left(-\omega / \tan (\tau \omega)^{*} \mathrm{t}_{\text {last }}\right)\left(\omega / \tan (\tau \omega)^{*}\left(S_{0}+S_{1}\right)+\mathrm{T}_{\text {bini }}\right) ; \\
S_{0}=\mu_{b}\left(\exp \left(\omega / \tan (\tau \omega)^{*} \mathrm{t}\right)-1\right) /(\omega / \tan (\tau \omega)) ; \\
S_{1}=\left(\mathrm{T}_{\text {blast }}{ }^{*} \exp \left(\omega / \tan (\tau \omega)^{*} \mathrm{t}_{\text {last }}\right)-\mathrm{T}_{\text {bini }}-\mu_{b} *\left(\exp \left(\omega / \tan (\tau \omega)^{*} \mathrm{t}_{\text {last }}\right)-1\right)\right) / \\
\omega / \tan (\tau \omega) /\left(-\exp \left(\omega * \mathrm{t}_{\text {last }}\right)^{*} \sin \left(-\omega *\left(\mathrm{t}_{\text {last }} \varphi\right)+\tau \omega\right)+\sin (\omega * \varphi+\tau \omega)\right)^{*} \\
\left(\exp \left(\omega / \tan (\tau \omega)^{*} \mathrm{t}\right) * \sin (\omega *(\mathrm{t}-\varphi)-\tau \omega)+\sin (\omega * \varphi+\tau \omega)\right) .
\end{gathered}
$$

Parameterization 5 (Body Temperature at $12 \mathrm{pm}$ - Median Time with lag): $\tau, \mathrm{T}_{\mathrm{bini}}, \mathrm{T}_{\mathrm{bm}}, \mu_{b}$. Because the model contains sinusoidal functions, $\mathrm{T}_{\text {blast }}$ might be the same as $\mathrm{T}_{\text {bini, }}$, initial body temperature. Therefore, another expected value parameterization would be to replace $t_{\text {blast }}$ with the median time, $t=t_{m e d}=13$, i.e. $12 \mathrm{pm}$ (figure2), Thus, $T_{\text {blast }}$ changes into $T_{b m}$, the body temperature when time is at the median time, $\mathrm{t}_{\text {med }}$. Therefore, the model will be:

$$
\begin{gathered}
T_{b}=\exp \left(-\omega / \tan (\tau \omega)^{*} \mathrm{t}_{\mathrm{med}}\right)\left(\omega / \tan (\tau \omega)^{*}\left(S_{0}+S_{1}\right)+\mathrm{T}_{\mathrm{bini}}\right) \\
S_{0}=\mu_{b}\left(\exp \left(\omega / \tan (\tau \omega)^{*} \mathrm{t}\right)-1\right) /(\omega / \tan (\tau \omega)) \\
S_{1}=\left(\mathrm{T}_{\mathrm{bm}} * \exp \left(\omega / \tan (\tau \omega)^{*} \mathrm{t}_{\mathrm{med}}\right)-\mathrm{T}_{\mathrm{bini}}-\mu_{b} *(\exp (\omega /\right. \\
\left.\left.\left.\tan (\tau \omega)^{*} \mathrm{t}_{\mathrm{med}}\right)-1\right)\right) / \omega / \tan (\tau \omega) /\left(-\exp \left(\omega * \mathrm{t}_{\mathrm{med}}\right) * \sin \left(-\omega^{*}\right.\right. \\
\left.\left.\left(\mathrm{t}_{\mathrm{med}} \varphi\right)+\tau \omega\right)+\sin (\omega * \varphi+\tau \omega)\right)^{*}(\exp (\omega / \\
\left.\left.\tan (\tau \omega)^{*} \mathrm{t}\right) * \sin (\omega *(\mathrm{t}-\varphi)-\tau \omega)+\sin (\omega * \varphi+\tau \omega)\right)
\end{gathered}
$$

Parameterization 6 (Log of Mean Body Temperature): $\tau, \mathrm{T}_{\mathrm{bini}}, \mathrm{T}_{\mathrm{bm}}, \mathrm{L} \mu_{\mathrm{b}}$. Following a rational similar to that used in step $5, \mathrm{~T}_{\mathrm{bm}}$ might be close to $\mu_{b}$. So, $\operatorname{L} \mu_{\mathrm{b}}=\operatorname{Ln}\left(\mu_{b}\right)$ can be used to replace $\mu_{b}$ to try to further reduce parameter effects curvature. The model will be: 


$$
\begin{gathered}
T_{b}=\exp \left(-\omega / \tan (\tau \omega)^{*} \mathrm{t}_{\mathrm{med}}\right)\left(\omega / \tan (\tau \omega)^{*}\left(S_{0}+S_{1}\right)+\mathrm{T}_{\mathrm{bini}}\right) ; \\
S_{0}=\exp \left(\mathrm{L} \mu_{\mathrm{b}}\right)\left(\exp \left(\omega / \tan (\tau \omega)^{* \mathrm{t}}\right)-1\right) /(\omega / \tan (\tau \omega)) \\
S_{1}=\left(\mathrm{T}_{\mathrm{bm}} * \exp \left(\omega / \tan (\tau \omega)^{*} \mathrm{t}_{\mathrm{med}}\right)-\mathrm{T}_{\mathrm{bini}}-\exp \left(\mathrm{L} \mu_{\mathrm{b}}\right) *(\exp (\omega /\right. \\
\left.\left.\left.\tan (\tau \omega)^{*} \mathrm{t}_{\mathrm{med}}\right)-1\right)\right) / \omega / \tan (\tau \omega) /\left(-\exp \left(\omega * \mathrm{t}_{\mathrm{med}}\right)^{*}\right. \\
\sin \left(-\omega *\left(\mathrm{t}_{\mathrm{med}} \varphi\right)+\tau \omega\right)+\sin (\omega * \varphi+ \\
\tau(\omega)) *\left(\exp \left(\omega / \tan (\tau \omega)^{*}\right) * \sin (\omega *(\mathrm{t}-\varphi)-\tau \omega)+\sin (\omega * \varphi+\tau \omega)\right) .
\end{gathered}
$$

Parameterization 7 (Body Temperature at 5:15am - Lower quartile with lag): $\tau, \mathrm{T}_{\text {bini }}, \mathrm{T}_{\mathrm{bq}}, \mu_{b}$. Use parameterization 5, keep $\mu_{b}$ in the model but replace the median time with the lower quartile time, $\mathrm{t}_{\mathrm{q}}$. Thus $\mathrm{t}_{\mathrm{bm}}$ becomes $\mathrm{t}_{\mathrm{bq}}$, and $\mathrm{T}_{\mathrm{bq}}$ is the body temperature when time is at the lower quartile of $\mathrm{t}$. The model is;

$$
\begin{gathered}
T_{b}=\exp \left(-\omega / \tan (\tau \omega)^{*} \mathrm{t}_{\mathrm{q}}\right)\left(\omega / \tan (\tau \omega)^{*}\left(S_{0}+S_{1}\right)+\mathrm{T}_{\text {bini }}\right) ; \\
S_{0}=\mu_{b}(\exp (\omega / \tan (\tau \omega) * \mathrm{t})-1) /(\omega / \tan (\tau \omega)) ; \\
S_{1}=\left(\mathrm{T}_{\mathrm{bq}} * \exp \left(\omega / \tan (\tau \omega) * \mathrm{t}_{\mathrm{q}}\right)-\mathrm{T}_{\mathrm{bini}}-\mu_{b} *\left(\exp \left(\omega / \tan (\tau \omega)^{*} \mathrm{t}_{\mathrm{q}}\right)-1\right)\right) / \omega / \tan (\tau \omega) /(- \\
\left.\exp \left(\omega * \mathrm{t}_{\mathrm{q}}\right) * \sin \left(-\omega *\left(\mathrm{t}_{\mathrm{q}} \varphi\right)+\tau \omega\right)+\sin (\omega * \varphi+\tau \omega)\right)^{*} \\
\left(\exp \left(\omega / \tan (\tau \omega)^{*}\right)^{*} \sin (\omega *(\mathrm{t}-\varphi)-\tau \omega)+\sin (\omega * \varphi+\tau \omega)\right) .
\end{gathered}
$$

Parameterization 8 (Body Temperature at 5:15am - Lower quartile with thermal constant): $\kappa$, $\mathrm{T}_{\mathrm{bini}}, \mathrm{T}_{\mathrm{bq}}, \mu_{b}$. Based on parameterization 3, keep $\kappa$ in model and replace the last time value, $\mathrm{t}_{\text {last }}$ with the lower quartile time, $\mathrm{t}_{\mathrm{q}}$. The parameter $\mathrm{T}_{\text {blast }}$ becomes $\mathrm{T}_{\mathrm{bq}}$, as in Parameterization 7 . Therefore, the model will be:

$$
\begin{gathered}
T_{b}=e^{-\kappa^{* t}}\left(\kappa^{*}\left(S_{0}+S_{1}\right)+\mathrm{T}_{\mathrm{bini}}\right) \\
S_{0}=\mu_{b}\left(e^{\kappa^{* t}}-1\right) / \kappa \\
S_{\mathrm{l}}=\left(\mathrm{T}_{\mathrm{bq}} * \exp \left(\kappa^{*} \mathrm{t}_{\mathrm{q}}\right)-\mathrm{T}_{\mathrm{bini}}-\mu_{b} *\left(\exp \left(\kappa^{*} \mathrm{t}_{\mathrm{q}}\right)-1\right)\right) / \kappa /\left(-\exp \left(* \mathrm{t}_{\mathrm{q}}\right) *\right. \\
\left.\sin \left(-\omega *\left(\mathrm{t}_{\mathrm{q}} \varphi\right)+\arctan (\omega / \kappa)\right)+\sin (\omega * \varphi+\arctan (\omega / \kappa))\right)^{*} \\
\left(\exp \left(\kappa^{*} \mathrm{t}\right) * \sin (\omega *(\mathrm{t}-\varphi)-\arctan (\omega / \kappa))+\sin (\omega * \varphi+\arctan (\omega / \kappa))\right) .
\end{gathered}
$$

Parameterization 9 (Body Temperature at 6pm- Peak Time): $\tau, \mathrm{T}_{\mathrm{bini}}, \mathrm{T}_{\mathrm{bp}}, \mu_{b}$. Begin with parameterization 7 , replace the lower quartile time, $\mathrm{t}_{\mathrm{q}}$ with the peak time, $\mathrm{t}_{\mathrm{p}}$, i.e the time when body temperature is expected to be the highest. Maximum air temperature was set at $2 \mathrm{pm}$ (figure1) and body temperature may be expected to lag 4 hours behind air temperature (Hahn et al. 1997). So, let the peak time, $t_{p}=19(6 \mathrm{pm})$ since observations begin at 0:00am (figures 1 and 2). The body temperature becomes $\mathrm{T}_{\mathrm{bp}}$. Therefore, the model is:

$$
\begin{gathered}
T_{b}=\exp \left(-\omega / \tan (\tau \omega)^{*} \mathrm{t}_{\mathrm{p}}\right)\left(\omega / \tan (\tau \omega)^{*}\left(S_{0}+S_{1}\right)+\mathrm{T}_{\mathrm{bini}}\right) ; \\
S_{0}=\mu_{b}\left(\exp \left(\omega / \tan (\tau \omega)^{*} \mathrm{t}\right)-1\right) /(\omega / \tan (\tau \omega)) ; \\
S_{1}=\left(\mathrm{T}_{\mathrm{bp}} * \exp \left(\omega / \tan (\tau \omega)^{*} \mathrm{t}_{\mathrm{p}}\right)-\mathrm{T}_{\mathrm{bini}}-\mu_{b} *\left(\exp \left(\omega / \tan (\tau \omega) * \mathrm{t}_{\mathrm{p}}\right)-1\right)\right) / \omega / \tan (\tau \omega) /(- \\
\left.\exp \left(\omega * \mathrm{t}_{\mathrm{p}}\right) * \sin \left(-\omega *\left(\mathrm{t}_{\mathrm{p}} \varphi\right)+\tau \omega\right)+\sin (\omega * \varphi+\tau \omega)\right)^{*}\left(\exp \left(\omega / \tan (\tau \omega)^{*}\right) * \sin (\omega *(\mathrm{t}-\varphi)-\right. \\
\tau \omega)+\sin (\omega * \varphi+\tau \omega)) .
\end{gathered}
$$




\section{2.c Parameter Reduction}

Parameterization 10: (Reduced model) $K, \mathrm{~T}_{\text {bini }}, \Delta$. The high correlation between $\Delta$ and $\gamma$ may indicate the model is over-parameterized. When $\gamma$, the proportion of air temperature passed on to the body, is set to be the ratio of the amplitudes, $T_{b} / T_{a}$ and approximated by $\kappa / \sqrt{\kappa^{2}+\omega^{2}}$ the number of parameters is then reduced by one. The model becomes:

$$
T_{b}=e^{-\kappa^{*} t}\left(K^{*}\left(S_{0}+S_{1}\right)+T_{\text {bini }}\right)
$$

where $T_{\text {bini }}$ is the initial body temperature (treated as a random effect);

$$
\begin{gathered}
S_{0}=\left(\mu_{a}^{*} \kappa / \sqrt{\kappa^{2}+\omega^{2}}+\Delta\right)^{*}\left(e^{\kappa^{* t}}-1\right) / \kappa \\
S_{1}=\mathrm{A}^{*} \kappa /\left(k^{2}+\omega^{2}\right)^{*} e^{\kappa^{* t}}(\sin (\omega(\mathrm{t}-\varphi-\{\arctan (\omega / \kappa)\} / \omega)) \\
+\sin (\omega(\varphi+\{\arctan (\omega / \kappa)\} / \omega)))
\end{gathered}
$$

Paramertization 11 (Reduced model- $\left.\mu_{b}\right) \kappa, \mathrm{T}_{\text {bini }}, \mu_{b}$. Based on parameterization $10, \mu_{b}$ can be used to replace $\Delta$ since $\Delta=\mu_{b}-\gamma \mu_{a}$ and to obtain the following model:

$$
\begin{gathered}
T_{b}=e^{-\kappa^{* t}}\left(\kappa^{*}\left(S_{0}+S_{1}\right)+\mathrm{T}_{\mathrm{bini}}\right), \\
S_{0}=\mu_{b} *\left(e^{\kappa^{* t}}-1\right) / \kappa ; \\
S_{1}=\mathrm{A} * \kappa /\left(\kappa^{2}+\omega^{2}\right)^{*} e^{\kappa^{* t}}(\sin (\omega(\mathrm{t}-\varphi-\{\arctan (\omega / \kappa)\} / \omega)) \\
+\sin (\omega(\varphi+\{\arctan (\omega / \kappa)\} / \omega))) ;
\end{gathered}
$$

Parameterization 12: (Reduced model- $\tau$ ) $\tau, \mathrm{T}_{\text {bini }}, \mu_{b}$. Based on the parameterization 11 model, $\tau$ can be used to replace $\kappa$ by $K=\omega / \tan (\tau \omega)$ and obtain the following model:

$$
\begin{aligned}
& T_{b}=\exp (-\omega \mathrm{t} / \tan (\tau \omega))\left(\omega / \tan (\tau \omega) *\left(S_{0}+S_{1}\right)+\mathrm{T}_{\mathrm{bini}}\right), \\
& S_{0}=\mu_{b} *(\exp (\omega \mathrm{t} / \tan (\tau \omega))-1) / \omega / \tan (\tau \omega) ; \\
& S_{1}=\mathrm{A} * \mathrm{t}^{*} \tan (\tau \omega) /\left(\omega * ( 1 + \operatorname { t a n } ( \tau \omega ) ^ { * * 2 } ) * \left(\exp (\omega \mathrm{t} / \tan (\tau \omega))^{*}\right.\right. \\
& (\sin (\omega(\mathrm{t}-\varphi-\tau))+\sin (\omega(\varphi+\tau)))
\end{aligned}
$$

Parameterization 13 (Reduced model-6pm Peak Time) $K, \mathrm{~T}_{\mathrm{bini}}, \mathrm{T}_{\mathrm{bp}}$. Similar to parameterization 3 , use an expected-value parameterization to replace $\mu_{b}$ based on the model with Parameterization 11. First set $t=t_{p}=19$ and real time is at $6 \mathrm{pm}$ i.e. the time when body temperature reaches the peak (figures 1, 2) and the body temperature at that time is $T_{b p}$. Substitute the two variables into the model with parameterization 11 and solve parameter $\mu_{b}$ in terms of $t_{p}, T_{b p}$ and the other parameters. Finally, $\mathrm{T}_{\mathrm{bp}}$ can be used to replace $\mu_{b}$ via the solved equation to obtain the reparameterized model:

$$
\begin{aligned}
& T_{b}=e^{-\kappa^{*} t}\left(\kappa^{*}\left(S_{0}+S_{1}\right)+\mathrm{T}_{\text {bini }}\right), \\
& S_{0}=\mu_{b}^{*}\left(e^{\kappa^{*} t}-1\right) / \kappa \text {; }
\end{aligned}
$$

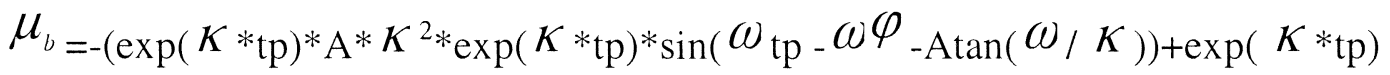

$$
\begin{aligned}
& * \mathrm{~A} * K^{2} * \sin (\omega * \varphi+\operatorname{Atan}(\omega / K))+\exp (-K * \operatorname{tp}) * \operatorname{Tini} * K^{2}+\exp (-K * \operatorname{tp}) * \operatorname{Tini} * \omega^{2}-
\end{aligned}
$$




$$
\begin{gathered}
\text { Tbp* } \left.K^{2}-\mathrm{Tbp}^{*} \omega^{2}\right) / \exp (-\kappa * \operatorname{tp}) /\left(\exp (-\kappa * \operatorname{tp}) * \kappa^{2}+\exp (\kappa * \operatorname{tp})^{*} \omega^{2}-K^{2}-\omega^{2}\right) \\
S_{1}=\mathrm{A} * \kappa /\left(\kappa^{2}+\omega^{2}\right) * e^{\kappa^{*} t}(\sin (\omega(\mathrm{t}-\varphi-\{\arctan (\omega / \kappa)\} / \omega))+ \\
\sin (\omega(\varphi+\{\arctan (\omega / \kappa)\} / \omega))) ;
\end{gathered}
$$

Parameterization 14 (Reduced model-6pm Peak Time with $\tau$ ) $\tau, \mathrm{T}_{\text {bini }}, \mathrm{T}_{\mathrm{bp}}$, . Use $\tau$ to replace $\kappa$ based on the model with Parameterization 13 and obtain the following model:

$$
\begin{aligned}
& T_{b}=e^{-\kappa^{* t}}\left(\kappa^{*}\left(S_{0}+S_{1}\right)+\mathrm{T}_{\mathrm{bini}}\right) \text {, } \\
& S_{0}=\mu_{b} *\left(e^{\kappa^{* t}}-1\right) / \kappa \\
& \kappa=\omega / \tan (\tau \omega)
\end{aligned}
$$

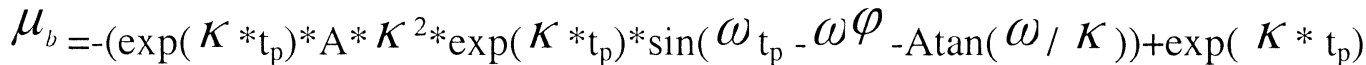

$$
\begin{aligned}
& * \mathrm{~A} * K^{2} * \sin (\omega * \varphi+\operatorname{Atan}(\omega / K))+\exp \left(-\kappa * \mathrm{t}_{\mathrm{p}}\right) * \operatorname{Tini} * K^{2}+\exp \left(-\kappa * \mathrm{t}_{\mathrm{p}}\right) * \operatorname{Tini} * \omega^{2} \\
& \text { - Tbp } \left.* K^{2}-\mathrm{Tbp}^{*} \omega^{2}\right) / \exp \left(-\kappa * \mathrm{t}_{\mathrm{p}}\right) /\left(\exp \left(-\kappa * \mathrm{t}_{\mathrm{p}}\right) * \kappa^{2}+\exp \left(\kappa * \mathrm{t}_{\mathrm{p}}\right) * \omega^{2}-K^{2}-\omega^{2}\right) \\
& S_{1}=\mathrm{A} * \kappa /\left(\kappa^{2}+\omega^{2}\right) * e^{\kappa^{*} t}(\sin (\omega(\mathrm{t}-\varphi-\{\arctan (\omega / \kappa)\} / \omega))+ \\
& \sin (\omega(\varphi+\{\arctan (\omega / \kappa)\} / \omega)))
\end{aligned}
$$

Parameterization 15 (Reduced model at 5:15am Lower quartile with $K$ ) $K, \mathrm{~T}_{\text {bini }}, \mathrm{T}_{\text {bq }}$. Set $t=t_{p}$, lower quartile time and $T_{b}=T_{b q}$ i.e. the body temperature at $t_{p}$ and then repeat the procedure in the Parameterization 13 and obtain the following model:

$$
\begin{aligned}
& T_{b}=e^{-\kappa^{*} t}\left(\kappa^{*}\left(S_{0}+S_{1}\right)+\mathrm{T}_{\text {bini }}\right) \text {, } \\
& S_{0}=\mu_{b} *\left(e^{\kappa^{* t}}-1\right) / \kappa \text {; }
\end{aligned}
$$

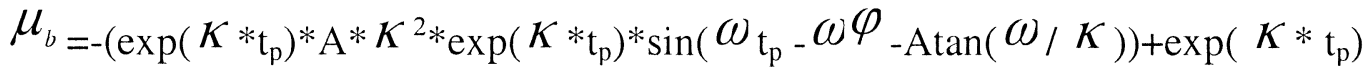

$$
\begin{aligned}
& * \mathrm{~A} * K^{2} * \sin \left(\omega * \varphi_{+} \operatorname{Atan}(\omega / K)\right)+\exp \left(-\kappa * \mathrm{t}_{\mathrm{p}}\right) * \operatorname{Tini} * K^{2}+\exp \left(-\kappa * \mathrm{t}_{\mathrm{p}}\right) * \mathrm{Tini}^{*} \omega^{2} \\
& \text { - Tbq } \left.* K^{2}-\mathrm{Tbq}^{*} \omega^{2}\right) / \exp \left(-K * \mathrm{t}_{\mathrm{p}}\right) /\left(\exp \left(-K * \mathrm{t}_{\mathrm{p}}\right) * K^{2}+\exp \left(K * \mathrm{t}_{\mathrm{p}}\right) * \omega^{2}-K^{2}-\omega^{2}\right) \\
& S_{1}=\mathrm{A}^{*} \kappa /\left(\kappa^{2}+\omega^{2}\right)^{*} e^{\kappa^{* t}}(\sin (\omega(\mathrm{t}-\varphi-\{\arctan (\omega / \kappa)\} / \omega))+ \\
& \sin (\omega(\varphi+\{\arctan (\omega / \kappa)\} / \omega))) \text {; }
\end{aligned}
$$

Parameterization 16 (Reduced model at 5:15am - Lower quartile with $\tau$ ) $\tau, \mathrm{T}_{\mathrm{bini}}, \mathrm{T}_{\mathrm{bq}}$.

Use $\tau$ to replace $K$ based on the model with Parameterization 15 and obtain the following model:

$$
\begin{aligned}
& T_{b}=e^{-K^{*} t}\left(K^{*}\left(S_{0}+S_{1}\right)+\mathrm{T}_{\text {bini }}\right) \text {, } \\
& S_{0}=\mu_{b}^{*}\left(e^{\kappa^{* t}}-1\right) / \kappa \\
& \kappa=\omega / \tan (\tau \omega)
\end{aligned}
$$

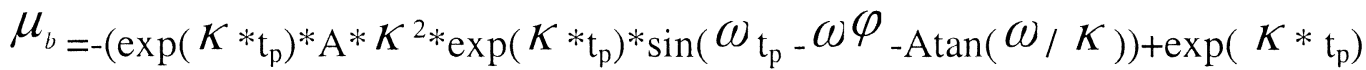

$$
\begin{aligned}
& * \mathrm{~A} * K^{2} * \sin (\omega * \varphi+\operatorname{Atan}(\omega / K))+\exp \left(-\kappa * \mathrm{t}_{\mathrm{p}}\right) * \operatorname{Tini} * K^{2}+\exp \left(-\kappa * \mathrm{t}_{\mathrm{p}}\right) * \operatorname{Tini}^{*} \omega^{2} \\
& \text { - Tbq* } \left.K^{2}-\mathrm{Tbq} * \omega^{2}\right) / \exp \left(-K * \mathrm{t}_{\mathrm{p}}\right) /\left(\exp \left(-\kappa * \mathrm{t}_{\mathrm{p}}\right) * \kappa^{2}+\exp \left(\kappa * \mathrm{t}_{\mathrm{p}}\right) * \omega^{2}-K^{2}-\omega^{2}\right) \\
& S_{1}=A^{*} \kappa /\left(\kappa^{2}+\omega^{2}\right)^{*} e^{\kappa^{*} t}(\sin (\omega(\mathrm{t}-\varphi-\{\arctan (\omega / \kappa)\} / \omega))+
\end{aligned}
$$




\section{2.d Assessing Nonlinear behavior}

$$
\sin (\omega(\varphi+\{\arctan (\omega / \kappa)\} / \omega)))
$$

Nonlinear models have two curvature components: intrinsic and parameter-effect, curvature. Changing the parameterization alters the degree of parameter-effects curvature. The smaller the curvature of a model, the more the estimates behave like the efficient estimators in a linear model and the more reliable the inferential and diagnostic procedures (Schabenger and Pierce, 2000).

The parameter-effects curvature is a measure of the lack of parallelism and the inequality of spacing of parameter lines on the expectation surface. The root mean square parameter effects curvature $\mathrm{C}^{\theta}$ is a scalar quantity, representing the square root of the average over all directions of the squared curvature. When a $95 \%$ confidence disk is used as a scale of reference, $\mathrm{C}^{\theta *} \sqrt{F_{0.05}}$ can be compared to the deviation of the expectation surface with a radius $1 / \mathrm{C}$ from the tangent plane at a distance of $\sqrt{F_{0.05}}$ from the tangent point. If parameter effects $C^{\theta}$ is so small that $\mathrm{PE}=C^{\theta} * \sqrt{F_{0.05}}$ is close to 0.4 (a deviation of $21 \%$ ), the linear approximation inference regions will be acceptable (Bates and Watts, 1980). Similar reasoning holds for the standardized intrinsic curvature, IN.

\section{2.e Data Analysis}

Nonlinear regressions were performed to estimate the parameters, standard errors, confidence intervals and correlations for each parameterization, (proc NLIN, SAS, 1999). Proc GPLOT was used to graph the observations and predicted curves for $T_{a}$ and $T_{b}$. The asymptotic properties and curvatures were calculated by writing code for functions of the first and second derivatives in proc IML. Maple (1981) was used to obtain the formulas for the derivatives.

\section{Results and Discussions}

The intrinsic root mean square curvatures are acceptable both the original and reduced models (IN $=0.025708$ and 0.016469 , respectively). The parameter effects root mean square curvature PE are given in Table 1. For the four parameter (full) model, the direct relationship parameterizations, 1 and 2 leave the original parameter effects curvature essentially unchanged at 1.26. The expected value parameterizations gave mixed results. Parameterizations involving body temperature at the last time, 0:00am the next day, were disappointing. The parameter effects curvature increased drastically for parameterizations [3\&4], $(\mathrm{PE}=2.1935$ and $\mathrm{PE}=2.3166$ for $\kappa$ and $\tau$, respectively). Using body temperature at the median time of $12 \mathrm{pm}$ provides an improvement by lowering PE to 0.8636 for parameterization 5 with, lag $\tau$. But reparameterizing parm5 model by taking the log of $\mu_{\mathrm{b}}$ destroys the improvement and raises PE to 2.2334 for parameterization 6 . The expected value parameterizations $[7,8,9]$ involving body temperature at lower quartile time of 5:15am and the peak time of $6 \mathrm{pm}$ further improves the curvature $(\mathrm{PE} \leq 0.6156)$. But, only the lower quartile parameterizations [7\&8] (Body Temperature at 6:15am): parm7 with lag $\tau$, and parm 8 with thermal constant $\kappa$ have barely acceptable parameter effects curvature $(0.4420,0.4492$ for $\tau$ and $\kappa)$. 
For the reduced model, all parameterizations have acceptable parameter effects curvature. Replacing $\Delta$ with $\mu_{b}$ improves the PE (0.06) with either $\kappa$ or $\tau$ models [11\&12]. Once again the expected value parameterizations give mixed results, although all PE's were $<0.4$. The PE increased for the 5:15am lower quartile models,[15\&16] $(0.0886,0.0908$ for $\kappa$ and $\tau)$. While both $6 \mathrm{pm}$ peak models [13\&14] had the lowest PE (0.04) of all parameterizations.

The asymptotic properties as well as the parameter estimates and correlations are shown in Tables 2-12. For the original parameterization, the linear approximation is questionable because $\mathrm{T}_{\text {bini }}$, has a $\%$ excess variance $=6.256, \gamma$ has $\%$ bias $=2.841$, and $\%$ excess variance $=$ 6.326. The values of all these asymptotic properties are $>1$ indicating deviations from the close to linear assumption. Furthermore, $K$ is highly correlated with $\Delta$ and $\gamma(0.921,-0.930$, respectively), and $\Delta$ is highly correlated with $\gamma(0.999)$ suggesting over-parameterization (table2). Therefore, the original parameterization is unacceptable for this model-data set.

Parameterizations 1 and 2 are direct relationship parameterizations. In parameterization 1 , $\Delta$ was replaced by $\mu_{b}$ based on the original model. The parameterization improved $\%$ excess variance for $\mathrm{T}_{\text {bini }}(0.132)$ and the correlation between $\mu_{b}$ and $\gamma(0.191)$. But the $\%$ excess variance for $\mu_{b}$ (3.671), \% bias for $\gamma$ (2.841) and \% excess variance for $\gamma$ (6.325) are still greater than 1 and $K$ is still highly correlated with $\gamma(-0.930)$ (table 3$)$. In parameterization $2, \gamma$ was replaced by $\mu_{b}$ based on the original model. The results (not shown) were the same as for parameterization 1 (table 3 ) except for $\Delta$. For the parameter $\Delta$, the $\%$ bias $(-0.572)$ improved but the $\%$ excess variance (6.256) did not; and, $K$ is highly correlated with $\Delta(0.920)$. Therefore, parameterizations 1 and 2 are unacceptable for this model.

Parameterizations 3-9 are combinations of expected value parameterizations and direct relationships. In parameterization 3 (Last time- $\kappa$ ), $\Delta$ was replaced by expected value $T_{\text {blast }}$ at last time, i.e. $t=25$ based on the model with parameterization 2 . The parameterization reduced all correlations $(\leq 0.85$ ) (table 4 ) and all parameter estimates are closer to linear in behavior except $\mu_{b}$ (\% excess variance $\left.=3.675\right)$. But, the parameterization is still unacceptable because $\mathrm{PE}=$ 2.1935 (table1). Similarly, when $K$ was replaced by $\tau$, parameterization 4 (Last time- $\tau$ ), the asymptotic properties (results not shown) were acceptable except for $\%$ excess variance $\mu_{\mathrm{b}}$ and the PE assumptions were violated.

Parameterization 5 (Median time- $\tau$ ) is based on parameterization 4 , only $\mathrm{T}_{\text {blast }}$ was replaced by $T_{b m}$, the body temperature at median time, $t_{m e d}=13$. This parameterization further reduced the correlation between the expected value parameter $\left(\mathrm{T}_{\mathrm{bm}}\right)$ and $\mu_{b}(0.195)$ (table 5), but again $\%$ excess variance $\mu_{\mathrm{b}}>1$.

When $\mu_{b}$ was replaced by $\log \left(\mu_{\mathrm{b}}\right)$, parameterization $6\left(\log \mu_{b}\right)$, there was a dramatic increase in \% excess variance $\mu_{\mathrm{b}}$ (25.877) (table 6) as well as the PE (2.2334). This is the worse parameterization in the study. 
In parameterization 7 (5:15am Lower quartile $-\tau), \mathrm{T}_{\mathrm{bm}}$ was replaced by $\mathrm{T}_{\mathrm{bq}}$, the body temperature at the lower quartile time, $\mathrm{t}_{\mathrm{q}}$ based on the model with parameterization 5 . The behavior of this parameterization is similar to parameterization 5: it reduced the correlations between any two parameters ( $\leq 0.762$ ); and, all estimates indicated close to linear behavior except for $\%$ excess variance for parameter $\mu_{b}$ (3.674)(table 7). More importantly, the $\mathrm{PE}=0.4420$ was very close to the criterion value (0.4). So, parameterization 7 , Lower quartile with lag, is an acceptable version of the model. Similar results are obtained when $\tau$ is replaced by $\kappa$. So, parameterization 8 , (results not shown) (5:15am Lower quartile with thermal constant $\kappa)$, is also an acceptable version of the model.

In parameterization $9(6 \mathrm{pm}$ Peak time- $\tau), \mathrm{T}_{\mathrm{bq}}$ was replaced by $\mathrm{T}_{\mathrm{bp}}$, the body temperature at the peak time, $t_{p}=19$ based on the model with parameterization 7 . This parameterization didn't make any essential changes in asymptotic properties and correlations (table 8). But since $\mathrm{PE}=$ 0.6156, the peak time parameterization (9) is not as acceptable as parameterizations (7 and 8) based on the lower quartile.

For the reduced model, all parameterizations have well behaved asymptotic properties. The main focus is on the correlations. Parameterization 10: (Reduced model) $K, \mathrm{~T}_{\text {bini }}, \Delta$ still has a high correlation between $K$ and $\Delta(-0.992)$ (table 9$)$. So, this model is less than ideal.

Replacing $\Delta$ with $\mu_{\mathrm{b}}$ as in parameterization 11: (Reduced model- $\mu_{b}$ ) $\kappa, \mathrm{T}_{\text {bini }}, \mu_{b}$ and parameterization 12: (Reduced model- $\tau$ ) $\tau$, $\mathrm{T}_{\mathrm{bini}}, \mu_{b}$, reduces the correlations to less than 0.815 (table 10). More specifically, the |correlation| between $K$ (or $\tau)$ and $\mu_{b}$ is $(0.626)$ So, parameterizations using $\mu_{b}$ are more acceptable than those using $\Delta$.

When expected value parameterizations are used, the correlations are reduced still further. For peak time $(6 \mathrm{pm})$, the correlations are less than 0.739 for both $\kappa$ and $\tau$, reduced models [parameterizations 13 (table 11) and 14(results not shown)]. The results based on the lower quartile (5:15am) are similar [parameterizations 15 (table 12) and 16 (results not shown)]. While the correlations are comparable, the peak time models are preferred because they have the smallest PE.

\section{Conclusions}

For the full PET model, parameterizations based on direct substitution showed little effect on (or in some cases actually worsened) the nonlinear behavior, However, the expected value parameterizations showed great improvement in nonlinear behavior and asymptotic properties. Most notably, parameterizations based on the lower quartile had the lowest PE (0.44).

Parameterization 7 (Body Temperature at 5:15am - Lower quartile with lag: $\tau, \mathrm{T}_{\text {bini }}, \mathrm{T}_{\mathrm{bq}}$, $\mu_{b}$ ) is the best four parameter formulation studied. The validity of the linear approximation is strong. The parameter effects curvature is greatly reduced and all estimates (except \% excess variation for $\mu_{\mathrm{b}}$ ) are closer to linear in behavior. Moreover, after the reparameterization, the high correlations between parameters are reduced. This increases the stability of the model and the validity of simultaneous confidence intervals. Finally, the interpretation of the parameters $\mathrm{T}_{\text {bini }}$, 
$\mu_{b}, \tau, \mathrm{T}_{\mathrm{bq}}$ is more direct (using the lag, $\tau$ instead of the rate constant, $\kappa$ ): $\mathrm{T}_{\text {bini }}$ is initial body temperature at time zero; $\mu_{b}$ is $\mathrm{T}_{\mathrm{b}}$ mean body temperature; $\tau$ is the time it takes the $\mathrm{T}_{\mathrm{b}}$ to respond to $\mathrm{T}_{\mathrm{a}}$ and is a function of the thermal constant. $\tau=(\arctan (\omega / \mathrm{K})) / \omega ; \mathrm{T}_{\mathrm{bq}}$ is the expected value of $\mathrm{T}_{\mathrm{b}}$ when $\mathrm{t}$ is at the lower quartile. For example, the data used in this study, consisted of a total of 25 hours, since the analysis started at 0:00am and continued until 0:00am the next day. Thus, $\mathrm{T}_{\mathrm{bq}}$ is the expected body temperature of the steer when $\mathrm{t}=6.25$, i.e. at $5: 15$ am.

For the reduced model all parameterizations adhere to the nonlinear assumptions $(\mathrm{PE}<0.01)$ but the peak time formulations are better than rest $(\mathrm{PE}<0.045)$. All parameterizations exhibited close to linear behavior. The only concern is the high correlations when $\Delta$ is used. The correlations were reduced by either direct substitution to $\mu_{\mathrm{b}}$ or expected value parameterizations. Parameterization 14 (Reduced model-6pm Peak time): $\tau, \mathrm{T}_{\mathrm{bini}}, \mathrm{T}_{\mathrm{bp}}$ is considered the best of the best because the lag, $\tau$ is easy to interpret.

In general, when the heat challenge is a controlled sinusoidal function, the reduced model gives better parameterizations than those of the full model but it may not describe the data as well. The next step is to perform a simulation study to determine if these conclusions hold for this type of model-data combinations and to assess how well the models fit the data.

\section{Summary}

The original parameterization of the PET model indicates deviations from the assumptions needed for nonlinear parameter estimation. Two types of parameterization (direct substitution and expected value) were used to improve nonlinear behaviors, such as parametereffects curvature, bias, excess variance, and skewness, and reduce the correlation between parameters. The parameterizations were used on two versions of the model, full and reduced. The full model consisted of all four parameters involved in the original model. The reduced model was produced by assuming that $\gamma$, the proportion of air temperature passed on to the body, equals the ratio of the amplitudes, $T_{b} / T_{a}$, and can be approximated by $\kappa / \sqrt{\kappa^{2}+\omega^{2}}$ Of the nine full parameterizations studied, the two based on the Lower quartile (5am) expected value parameterizations provided acceptable versions of the model. Parameterization 7: (Lower quartile with $\operatorname{lag} \tau$ ) and parameterization 8:( Lower quartile with thermal constant), $K$, produced satisfactory parameter effects curvature and close to linear behavior for all estimates except $\mu_{b}$. However, $\tau$, the length of time (days) that $T_{b}$ lags behind $T_{a}$ can be considered a more desirable interpretation of the heat stress dynamics than $K$, the thermal constant that represents how rapidly $T_{b}$ adjusts to changes in $T_{a}$ in units of $1 / \mathrm{hr}$.

Of the seven reduced parameterizations studied, all had excellent nonlinear behavior. In addition, low correlations were produced by direct substitution (Reduced model $-\mu_{b}$ ) [parameterizations 11\&12] and expected value parameterizations both those based on lower quartile and those based on peak time The reduced peak time $(6 \mathrm{pm}): \tau, \mathrm{T}_{\text {bini }}, \mathrm{T}_{\mathrm{bp}}$ ) parameterization [14] was slightly preferred over the other three-parameters formulations. And the reduced model parameterizations were superior to those based on the full version of the model in terms of meeting nonlinear behavioral assumptions. 


\section{References}

Bates, D.M., and D.L. Watts. 1980. "Relative curvature measures of nonlinearity." J. R. Statist. Soc. Ser. B 42:1-25.

Hahn,G.L. 1989. "Body temperature rhythms in farm animals" Proceedings of $11^{\text {th }}$ ISB-Congrss .SPB Academic Publishing BV, The Hage, The Netherlands. 325-337.

Hahn, G.L., A.M. Parkhurst and J.B.Gaughan.1997. "Cattle respiration rate as a function of ambient temperature". ASAE Mid-Central Conf. Paper MC97-121, April, 1997.

Maple. 1981. Maple V Release 4.00a. Waterloo Maple Inc., Ontario, Canada. Parkhurst, A.M., G.L.Hahn, K.M.Eskridge, D.A.Travnicek, and H.D.Liu. 1999. "Predicting body temperature of cattle during stages of exposure to controlled hot cyclic air temperature using metrics with specified delays", Proceedings of the International Congress of Biometeorology \& International Conference on Urban Climatology Nov 8-12 p 274-280

Ratkowsky, D. A.. 1983. Nonlinear regression Modeling: Marcel Dekker, New York.

Ratkowsky, D. A.. 1990. Handbook of Nonlinear Regression Models. Marcel Dekker, New York. Pp75-82.

SAS. 1999. SAS/STAT User' s Guide. Version 8. SAS Institute Inc., Cary, NC.

Schabenberge, O. and Pierce, F,J.2000. Contemporary Statistical Models for the Plant and soil Sciences. CRC Press, New York. Pp 228-234. 
Table 1: Comparison of Standardized Parameter-effects Curvature, $\mathrm{PE}=C^{\theta} * \sqrt{\mathbf{F}_{0.05}}$, for All Parameterizations Studied

\begin{tabular}{|c|c|c|c|c|c|}
\hline Parameterization & $\mathrm{PE}$ & Parameterization & $\mathrm{PE}$ & Parameterization & $\mathrm{PE}$ \\
\hline $\begin{array}{l}\kappa, \mathrm{T}_{\text {bini }}, \Delta, \gamma \\
\quad \text { (Original) }\end{array}$ & 1.2601 & $\begin{array}{l}7: \tau, \mathrm{T}_{\mathrm{bini}}, \mathrm{T}_{\mathrm{bq}}, \mu_{b} \\
\text { (Lower quartile- } \tau \text { ) }\end{array}$ & 0.4420 & $\begin{array}{l}10: \kappa, \mathrm{T}_{\text {bini }}, \Delta \\
\text { (Reduced model) }\end{array}$ & 0.0908 \\
\hline $\begin{array}{c}1: \kappa, \mathrm{T}_{\text {bini }}, \mu_{b}, \gamma \\
(\text { Replace } \Delta)\end{array}$ & 1.2600 & $\begin{array}{l}8: \kappa, \mathrm{T}_{\text {bini }}, \mathrm{T}_{\mathrm{bq}}, \mu_{b} \\
(\text { Lower quartile- } \kappa)\end{array}$ & 0.4492 & $\begin{array}{r}11: \kappa, \mathrm{T}_{\text {bini }}, \mu_{b} \\
\text { (Reduced }-\mu_{b} \text { ) }\end{array}$ & 0.0624 \\
\hline $\begin{aligned} 2: & \kappa, \mathrm{T}_{\text {bini }}, \Delta, \mu_{b} \\
& (\text { Replace } \gamma)\end{aligned}$ & 1.2601 & $\begin{aligned} 9: & \tau, \mathrm{T}_{\mathrm{bini}}, \mathrm{T}_{\mathrm{bp}}, \mu_{b} \\
& (\text { Peak time- } \tau)\end{aligned}$ & 0.6156 & $\begin{array}{c}\text { 12: } \tau, \mathrm{T}_{\text {bini }}, \mu_{b} \\
\quad(\text { Reduced }-\tau)\end{array}$ & 0.0636 \\
\hline $\begin{array}{c}3: \kappa, \mathrm{T}_{\text {bini }}, \mathrm{T}_{\text {blast },} \mu_{b} \\
(\text { Last time- } \kappa)\end{array}$ & 2.1935 & & & $\begin{array}{c}\text { 13: } K, \mathrm{~T}_{\text {bini }}, \mathrm{T}_{\mathrm{bp}} \\
\text { (Reduced Peak } \mathrm{T}-K \text { ) }\end{array}$ & 0.0370 \\
\hline $\begin{array}{c}4: \tau, \mathrm{T}_{\text {bini }}, \mathrm{T}_{\text {blast }}, \mu_{b} \\
\quad(\text { Last time- } \tau \text { ) }\end{array}$ & 2.3166 & & & $\begin{array}{c}\text { 14: } \tau, \mathrm{T}_{\mathrm{bini}}, \mathrm{T}_{\mathrm{bp}} \\
\text { (Reduced Peak }-\tau \text { ) }\end{array}$ & 0.0416 \\
\hline $\begin{array}{c}\text { 5: } \tau, \mathrm{T}_{\text {bini }}, \mathrm{T}_{\mathrm{bm}}, \mu_{b} \\
(\text { Median time- } \tau \text { ) }\end{array}$ & 0.8636 & & & $\begin{array}{c}\text { 15: } \kappa, \mathrm{T}_{\text {bini }}, \mathrm{T}_{\mathrm{bq}} \\
\text { (Reduced }- \text { Lower quartile- } K \text { ) } \\
\end{array}$ & 0.0886 \\
\hline $\begin{array}{c}6: \tau, \mathrm{T}_{\mathrm{bini}}, \mathrm{T}_{\mathrm{bm},} \mathrm{L} \mu_{\mathrm{b}} \\
\left(\log \mu_{b}\right)\end{array}$ & 2.2334 & & & $\begin{array}{c}\text { 16: } \tau, \mathrm{T}_{\text {bini }}, \mathrm{T}_{\mathrm{bq}} \\
\text { (Reduced - Lower quartile- } \tau \text { ) }\end{array}$ & 0.0983 \\
\hline
\end{tabular}


Table 2: The Estimates of Parameters, their Asymptotic Properties and Correlations for Original Parameterization

\begin{tabular}{|c|c|c|c|c|c|c|c|c|c|c|}
\hline \multirow{2}{*}{ Parmeter } & \multirow{2}{*}{ Estimate } & \multirow{2}{*}{$\begin{array}{l}\text { Std } \\
\text { Error }\end{array}$} & \multirow{2}{*}{$\begin{array}{l}95 \% \text { Confidence } \\
\text { Interval }\end{array}$} & \multicolumn{3}{|c|}{ Asymptotic Properties } & \multicolumn{4}{|c|}{ Correlation } \\
\hline & & & & Skew & Bias \% & $\begin{array}{c}\% \text { Excess } \\
\text { Var }\end{array}$ & $\mathrm{K}$ & $\mathrm{T}_{\text {bini }}$ & $\Delta$ & $\gamma$ \\
\hline $\mathrm{K}$ & 0.079 & 0.015 & $0.048 \quad 0.111$ & 0.081 & 0.002 & 0.132 & 1.000 & 0.180 & 0.921 & -0.930 \\
\hline $\mathrm{T}_{\text {bini }}$ & 40.083 & 0.058 & $39.961 \quad 40.205$ & 0.026 & -0.572 & 6.256 & 0.180 & 1.000 & -0.117 & 0.089 \\
\hline$\Delta$ & 33.084 & 1.101 & $30.793 \quad 35.374$ & -0.953 & 0.253 & 0.338 & 0.921 & -0.117 & 1.000 & -0.999 \\
\hline$\gamma$ & 0.209 & 0.034 & 0.281 & 0.964 & 2.841 & 6.326 & -0.930 & 0.089 & -0.999 & 1.000 \\
\hline
\end{tabular}

Table 3: The Estimates of Parameters, their Asymptotic Properties and Correlations for Parameterization 1 (Replace $\Delta$ )

\begin{tabular}{|c|c|c|c|c|c|c|c|c|c|c|}
\hline \multirow{2}{*}{ Parmeter } & \multirow{2}{*}{ Estimate } & \multirow{2}{*}{$\begin{array}{l}\text { Std } \\
\text { Error }\end{array}$} & \multirow{2}{*}{$\begin{array}{l}95 \% \text { Confidence } \\
\text { Interval }\end{array}$} & \multicolumn{3}{|c|}{ Asymptotic Properties } & \multicolumn{4}{|c|}{ Correlation } \\
\hline & & & & Skew & Bias \% & $\begin{array}{c}\% \text { Excess } \\
\text { Var }\end{array}$ & $\mathrm{K}$ & $\mathrm{T}_{\text {bini }}$ & $\mu_{b}$ & $\gamma$ \\
\hline $\mathrm{K}$ & 0.079 & 0.015 & $0.048 \quad 0.111$ & 0.080 & 0.253 & 0.338 & 1.000 & 0.180 & -0.407 & -0.930 \\
\hline $\mathrm{T}_{\text {bini }}$ & 40.083 & 0.058 & $39.961 \quad 40.205$ & 0.026 & 0.001 & 0.132 & 0.180 & 1.000 & -0.762 & 0.089 \\
\hline$\mu_{b}$ & 39.856 & 0.040 & $39.772 \quad 39.940$ & 0.392 & 0.008 & 3.671 & -0.407 & -0.762 & 1.000 & 0.191 \\
\hline$\gamma$ & 0.209 & 0.034 & 0.281 & 0.961 & 2.841 & 6.325 & -0.930 & 0.089 & 0.191 & 1.000 \\
\hline
\end{tabular}


Table 4: The Estimates of Parameters, their Asymptotic Properties and Correlations in Parameterization 3 (Last time $\mathrm{T}_{\text {blast }}-K$ )

\begin{tabular}{|c|c|c|c|c|c|c|c|c|c|c|}
\hline \multirow{2}{*}{ Parmeter } & \multirow{2}{*}{ Estimate } & \multirow{2}{*}{$\begin{array}{l}\text { Std } \\
\text { Error }\end{array}$} & \multirow{2}{*}{$\begin{array}{c}95 \% \text { Confidence } \\
\text { Interval }\end{array}$} & \multicolumn{3}{|c|}{ Asymptotic Properties } & \multicolumn{4}{|c|}{ Correlation } \\
\hline & & & & Skew & Bias \% & $\begin{array}{c}\% \text { Excess } \\
\text { Var }\end{array}$ & $\mathrm{K}$ & $\mathrm{T}_{\text {bini }}$ & $\mathrm{T}_{\text {blast }}$ & $\mu_{b}$ \\
\hline $\mathrm{K}$ & 0.079 & 0.015 & $0.048 \quad 0.111$ & 0.080 & 0.253 & 0.338 & 1.000 & 0.180 & -0.795 & -0.407 \\
\hline $\mathrm{T}_{\text {bini }}$ & 40.083 & 0.058 & $39.961 \quad 40.205$ & 0.026 & 0.001 & 0.133 & 0.180 & 1.000 & -0.469 & -0.761 \\
\hline $\mathrm{T}_{\text {blast }}$ & 39.960 & 0.040 & $39.875 \quad 40.044$ & 0.065 & 0.000 & 0.118 & -0.795 & -0.469 & 1.000 & 0.850 \\
\hline$\mu_{b}$ & 39.856 & 0.040 & $39.772 \quad 39.940$ & 0.392 & 0.008 & 3.675 & -0.407 & -0.761 & 0.850 & 1.000 \\
\hline
\end{tabular}

Tables 5: The Estimates of Parameters, their Asymptotic Properties and Correlations in Parameterization $5\left(\right.$ Median time $\mathrm{T}_{\mathrm{bm}}-\tau$ )

\begin{tabular}{|c|c|c|c|c|c|c|c|c|c|c|}
\hline \multirow{2}{*}{ Parmeter } & \multirow{2}{*}{ Estimate } & \multirow{2}{*}{$\begin{array}{l}\text { Std } \\
\text { Error }\end{array}$} & \multirow{2}{*}{$\begin{array}{l}95 \% \text { Confidence } \\
\text { Interval }\end{array}$} & \multicolumn{3}{|c|}{ Asymptotic Properties } & \multicolumn{4}{|c|}{ Correlation } \\
\hline & & & & Skew & Bias \% & $\begin{array}{c}\% \text { Excess } \\
\text { Var }\end{array}$ & $\tau$ & $\mathrm{T}_{\text {bini }}$ & $\mathrm{T}_{\mathrm{bm}}$ & $\mu_{b}$ \\
\hline$\tau$ & 4.869 & 0.201 & $4.451 \quad 5.288$ & 0.015 & 0.010 & 0.303 & 1.000 & -0.180 & -0.726 & 0.407 \\
\hline $\mathrm{T}_{\text {bini }}$ & 40.083 & 0.058 & $39.961 \quad 40.205$ & 0.026 & 0.001 & 0.133 & -0.180 & 1.000 & -0.071 & -0.762 \\
\hline $\mathrm{T}_{\mathrm{bm}}$ & 39.760 & 0.026 & $39.706 \quad 39.815$ & 0.002 & 0.000 & 0.036 & -0.726 & -0.071 & 1.000 & 0.195 \\
\hline$\mu_{b}$ & 39.856 & 0.040 & $39.772 \quad 39.940$ & 0.392 & 0.008 & 3.674 & 0.407 & -0.762 & 0.195 & 1.000 \\
\hline
\end{tabular}


Table 6: The Estimates of Parameters, their Asymptotic Properties and Correlations in Parameterization $6\left(\log \mu_{b}\right)$

\begin{tabular}{|c|c|c|c|c|c|c|c|c|c|c|}
\hline \multirow{2}{*}{ Parmeter } & \multirow{2}{*}{ Estimate } & \multirow{2}{*}{$\begin{array}{l}\text { Std } \\
\text { Error }\end{array}$} & \multirow{2}{*}{$\begin{array}{c}95 \% \text { Confidence } \\
\text { Interval }\end{array}$} & \multicolumn{3}{|c|}{ Asymptotic Properties } & \multicolumn{4}{|c|}{ Correlation } \\
\hline & & & & Skew & Bias \% & $\begin{array}{c}\% \text { Excess } \\
\text { Var }\end{array}$ & $\tau$ & $\mathrm{T}_{\text {bini }}$ & $\mathrm{T}_{\mathrm{bm}}$ & $\log \mu_{\mathrm{b}}$ \\
\hline$\tau$ & 4.869 & 0.201 & $4.451 \quad 5.288$ & 0.015 & 0.010 & 0.303 & 1.000 & -0.180 & -0.726 & 0.408 \\
\hline $\mathrm{T}_{\text {bini }}$ & 40.083 & 0.058 & $39.961 \quad 40.205$ & 0.026 & 0.001 & 0.133 & -0.180 & 1.000 & -0.072 & -0.762 \\
\hline $\mathrm{T}_{\mathrm{bm}}$ & 39.760 & 0.026 & $39.706 \quad 39.815$ & 0.002 & 0.000 & 0.036 & -0.726 & -0.072 & 1.000 & 0.194 \\
\hline $\log \mu_{\mathrm{b}}$ & 3.685 & 0.0010 & $3.683 \quad 3.687$ & 0.315 & -0.007 & 25.877 & 0.408 & -0.762 & 0.194 & 1.000 \\
\hline
\end{tabular}

Table 7: he Estimates of Parameters, their Asymptotic Properties and Correlations in Parameterization 7 (Lower quartile $\mathrm{T}_{\mathrm{bq}}-\tau$ )

\begin{tabular}{|c|c|c|c|c|c|c|c|c|c|c|}
\hline \multirow{2}{*}{ Parmeter } & \multirow{2}{*}{ Estimate } & \multirow{2}{*}{$\begin{array}{l}\text { Std } \\
\text { Error }\end{array}$} & \multirow{2}{*}{$\begin{array}{l}95 \% \text { Confidence } \\
\text { Interval }\end{array}$} & \multicolumn{3}{|c|}{ Asymptotic Properties } & \multicolumn{4}{|c|}{ Correlation } \\
\hline & & & & Skew & Bias \% & $\begin{array}{c}\% \text { Excess } \\
\text { Var }\end{array}$ & $\tau$ & $\mathrm{T}_{\text {bini }}$ & $\mathrm{T}_{\mathrm{bq}}$ & $\mu_{b}$ \\
\hline$\tau$ & 4.869 & 0.201 & $4.451 \quad 5.288$ & 0.015 & 0.010 & 0.303 & 1.000 & -0.180 & 0.315 & 0.407 \\
\hline $\mathrm{T}_{\text {bini }}$ & 40.083 & 0.058 & $39.961 \quad 40.205$ & 0.026 & 0.002 & 0.133 & -0.180 & 1.000 & -0.080 & -0.762 \\
\hline $\mathrm{T}_{\mathrm{bq}}$ & 39.443 & 0.026 & $39.388 \quad 39.498$ & -0.004 & -0.000 & 0.026 & 0.315 & -0.080 & 1.000 & 0.371 \\
\hline$\mu_{b}$ & 39.856 & 0.040 & $39.772 \quad 39.940$ & 0.393 & 0.008 & 3.674 & 0.407 & -0.762 & 0.371 & 1.000 \\
\hline
\end{tabular}


Table 8: The Estimates of Parameters, their Asymptotic Properties and Correlations in Parameterization $9\left(\right.$ Peak time $\left.\mathrm{T}_{\mathrm{bp}}-\tau\right)$

\begin{tabular}{|c|c|c|c|c|c|c|c|c|c|c|c|}
\hline \multirow{2}{*}{ Parmeter } & \multirow{2}{*}{ Estimate } & \multirow{2}{*}{$\begin{array}{l}\text { Std } \\
\text { Error }\end{array}$} & \multirow{2}{*}{\multicolumn{2}{|c|}{$\begin{array}{l}95 \% \text { Confidence } \\
\text { Interval }\end{array}$}} & \multicolumn{3}{|c|}{ Asymptotic Properties } & \multicolumn{4}{|c|}{ Correlation } \\
\hline & & & & & Skew & Bias \% & $\begin{array}{c}\text { \% Excess } \\
\text { Var }\end{array}$ & $\tau$ & $\mathrm{T}_{\text {bini }}$ & $\mathrm{T}_{\mathrm{bp}}$ & $\mu_{b}$ \\
\hline$\tau$ & 4.869 & 0.201 & 4.451 & 5.288 & 0.015 & 0.010 & 0.303 & 1.000 & -0.180 & -0.249 & 0.407 \\
\hline $\mathrm{T}_{\text {bini }}$ & 40.083 & 0.058 & 39.961 & 40.205 & 0.026 & 0.001 & 0.133 & -0.180 & 1.000 & 0.320 & -0.762 \\
\hline $\mathrm{T}_{\mathrm{bp}}$ & 40.299 & 0.026 & 40.244 & 40.354 & 0.002 & 0.000 & 0.021 & -0.249 & 0.320 & 1.000 & 0.103 \\
\hline$\mu_{b}$ & 39.856 & 0.040 & 39.772 & 39.940 & 0.393 & 0.008 & 3.674 & 0.407 & -0.762 & 0.103 & 1.000 \\
\hline
\end{tabular}

Table 9: The Estimates of Parameters, their Asymptotic Properties and Correlations in Parameterization 10 (Reduced Model)

\begin{tabular}{|c|c|c|c|c|c|c|c|c|c|c|}
\hline \multirow{2}{*}{ Parmeter } & \multirow{2}{*}{ Estimate } & \multirow{2}{*}{$\begin{array}{l}\text { Std } \\
\text { Error }\end{array}$} & \multirow{2}{*}{\multicolumn{2}{|c|}{$\begin{array}{l}\text { 95\% Confidence } \\
\text { Interval }\end{array}$}} & \multicolumn{3}{|c|}{ Asymptotic Properties } & \multicolumn{3}{|c|}{ Correlation } \\
\hline & & & & & Skew & Bias \% & $\begin{array}{c}\text { \% Excess } \\
\text { Var }\end{array}$ & $\mathrm{K}$ & $\mathrm{T}_{\text {bini }}$ & $\Delta$ \\
\hline $\mathrm{K}$ & 0.066 & 0.0022 & 0.061 & 0.071 & -0.086 & -0.048 & 0.0483 & 1.000 & 0.737 & -0.992 \\
\hline $\mathrm{T}_{\text {bini }}$ & 40.078 & 0.056 & 39.960 & 40.195 & 0.015 & 0.000 & 0.0035 & 0.737 & 1.000 & -0.788 \\
\hline$\Delta$ & 31.939 & 0.281 & 31.356 & 32.522 & 0.115 & 0.016 & 0.0802 & -0.992 & -0.788 & 1.000 \\
\hline
\end{tabular}


Table 10: The Estimates of Parameters, their Asymptotic Properties and Correlations in Parameterization 11 (Reduced model- $\mu_{b}$ )

\begin{tabular}{|c|c|c|c|c|c|c|c|c|c|c|}
\hline \multirow{2}{*}{ Parmeter } & \multirow{2}{*}{ Estimate } & \multirow{2}{*}{$\begin{array}{l}\text { Std } \\
\text { Error }\end{array}$} & \multirow{2}{*}{\multicolumn{2}{|c|}{$\begin{array}{l}\text { 95\% Confidence } \\
\text { Interval }\end{array}$}} & \multicolumn{3}{|c|}{ Asymptotic Properties } & \multicolumn{3}{|c|}{ Correlation } \\
\hline & & & & & Skew & Bias \% & $\begin{array}{c}\text { \% Excess } \\
\text { Var }\end{array}$ & $\mathrm{K}$ & $\mathrm{T}_{\text {bini }}$ & $\mu_{b}$ \\
\hline $\mathrm{K}$ & 0.066 & 0.0022 & 0.061 & 0.071 & -0.086 & -0.048 & 0.048 & 1.000 & 0.737 & -0.626 \\
\hline $\mathrm{T}_{\text {bini }}$ & 40.078 & 0.056 & 39.960 & 40.195 & 0.015 & 0.000 & 0.003 & 0.737 & 1.000 & -0.815 \\
\hline$\mu_{b}$ & 39.872 & 0.044 & 39.779 & 39.965 & 0.113 & 0.002 & 0.141 & -0.626 & -0.815 & 1.000 \\
\hline
\end{tabular}

Table 11: The Estimates of Parameters, their Asymptotic Properties and

Correlations in Parameterization 13 (Reduced model- Peak Time with K)

\begin{tabular}{|c|c|c|c|c|c|c|c|c|c|}
\hline \multirow{2}{*}{ Parmeter } & \multirow{2}{*}{ Estimate } & \multirow{2}{*}{$\begin{array}{l}\text { Std } \\
\text { Error }\end{array}$} & \multirow{2}{*}{$\begin{array}{l}\text { 95\% Confidence } \\
\text { Interval }\end{array}$} & \multicolumn{3}{|c|}{ Asymptotic Properties } & \multicolumn{3}{|c|}{ Correlation } \\
\hline & & & & Skew & Bias \% & $\begin{array}{c}\text { \% Excess } \\
\text { Var }\end{array}$ & $\mathrm{K}$ & $\mathrm{T}_{\text {bini }}$ & $\mathrm{T}_{\mathrm{bp}}$ \\
\hline $\mathrm{K}$ & 0.066 & 0.002 & $0.061 \quad 0.071$ & -0.086 & -0.048 & -0.048 & 1.000 & 0.739 & 0.656 \\
\hline $\mathrm{T}_{\text {bini }}$ & 40.078 & 0.057 & $39.959 \quad 40.196$ & 0.015 & 0.000 & 0.003 & 0.739 & 1.000 & 0.330 \\
\hline $\mathrm{T}_{\mathrm{bp}}$ & 40.294 & 0.025 & $40.241 \quad 40.348$ & 0.003 & -0.000 & 0.005 & 0.656 & 0.330 & 1.000 \\
\hline
\end{tabular}


Table 12: The Estimates of Parameters, their Asymptotic Properties and

Correlations in Parameterization 15 (Reduced model- Lower quartile with K)

\begin{tabular}{|c|c|c|c|c|c|c|c|c|c|c|}
\hline \multirow{2}{*}{ Parmeter } & \multirow{2}{*}{ Estimate } & \multirow{2}{*}{$\begin{array}{l}\text { Std } \\
\text { Error }\end{array}$} & \multirow{2}{*}{\multicolumn{2}{|c|}{$\begin{array}{l}\text { 95\% Confidence } \\
\text { Interval }\end{array}$}} & \multicolumn{3}{|c|}{ Asymptotic Properties } & \multicolumn{3}{|c|}{ Correlation } \\
\hline & & & & & Skew & Bias \% & $\begin{array}{c}\text { \% Excess } \\
\text { Var }\end{array}$ & $\mathrm{K}$ & $\mathrm{T}_{\text {bini }}$ & $\mathrm{T}_{\mathrm{bq}}$ \\
\hline $\mathrm{K}$ & 0.066 & 0.002 & 0.061 & 0.071 & -0.086 & -0.048 & 0.048 & 1.000 & 0.739 & -0.669 \\
\hline $\mathrm{T}_{\text {bini }}$ & 40.078 & 0.057 & 39.959 & 40.196 & 0.015 & 0.000 & 0.003 & 0.739 & 1.000 & -0.055 \\
\hline $\mathrm{T}_{\mathrm{bq}}$ & 39.449 & 0.025 & 39.396 & 39.502 & -0.005 & -0.000 & 0.005 & -0.669 & -0.055 & 1.000 \\
\hline
\end{tabular}

Figure1. Observations and Curve of Original Model for Air Temperature vs Time

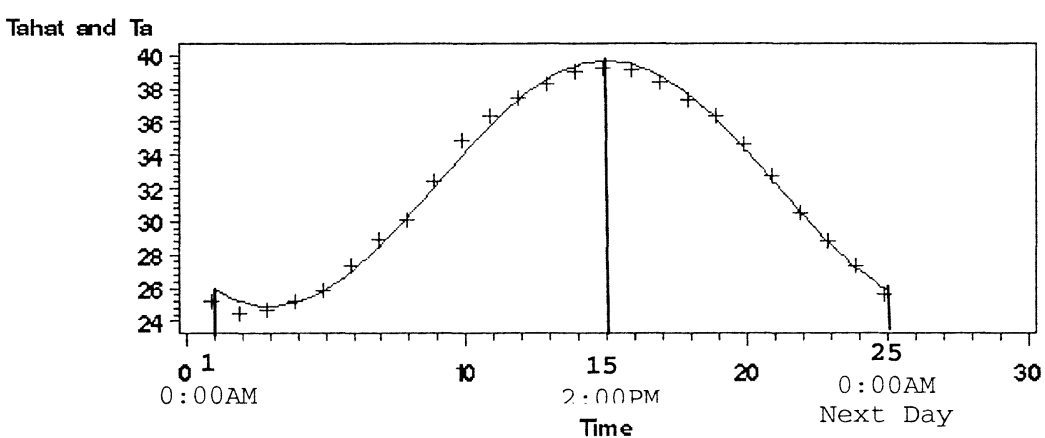

Figure 2. Observations and Predicted Curve of Original Model for Body Temperature vs Time

Thhat and $\mathrm{Tb}$

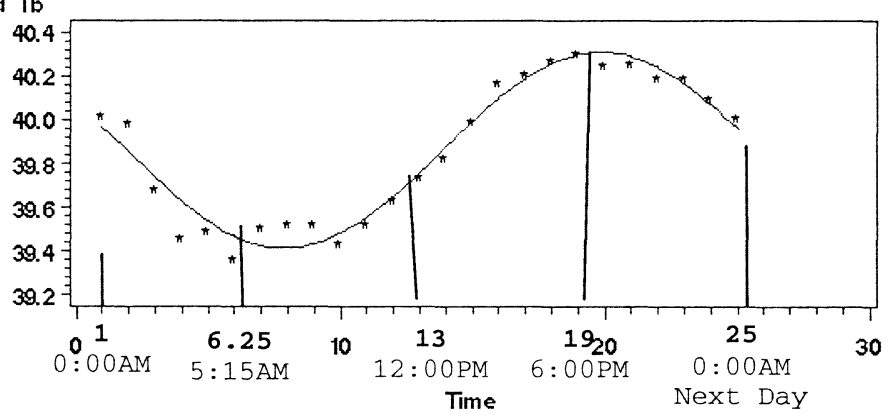

